\title{
CADEIA PRODUTIVA DO CHÁ-DE-BUGRE (Casearia sylvestris) NA REGIÃO METROPOLITANA DE CURITIBA - PARANÁ
}

\author{
Dalvo Ramires Balzon ${ }^{1}$, Anadalvo Juazeiro dos Santos², Cirino Corrêa Júnior ${ }^{3}$, \\ Alexandre Muzy Bittencourt ${ }^{4}$, Alexandre Nascimento de Almeida ${ }^{5}$ \\ ${ }^{1}$ Economista, Dr., Instituto Brasileiro de Pós-graduação e Extensão, IBPEX, SPEI, Curitiba, PR, Brasil - dalvo.rb@terra.com.br \\ ${ }^{2}$ Eng. Florestal, Dr., Depto. de Economia Rural e Extensão, UFPR, Curitiba, PR, Brasil - ajsantos@ufpr.br \\ ${ }^{3}$ Eng. Agrônomo, Dr., EMATER, Curitiba, PR, Brasil - plamed@emater.pr.gov.br \\ ${ }^{4}$ Eng. Florestal, M.Sc., Doutorando em Engenharia Florestal, UFPR, Curitiba, PR, Brasil - alexbitten@terra.com.br \\ ${ }^{5}$ Eng. Florestal, M.Sc., Doutorando em Engenharia Florestal, UFPR, Curitiba, PR, Brasil - alexfloresta@pop.com.br
}

Recebido para publicação: 13/09/2007 - Aceito para publicação: 10/04/2008

\begin{abstract}
Resumo
Este artigo aborda a produção e comercialização de Produtos Florestais Não-Madeireiros (PFNM), que ocorreu nos municípios de Curitiba, Campo Largo, Araucária e São José dos Pinhais, entre os meses de agosto e dezembro de 2005. O objetivo principal deste estudo foi analisar a cadeia produtiva do chá-debugre (Casearia sylvestris) como planta medicinal. A metodologia consistiu na aplicação de formulários junto aos produtores, nos quais foram abordados aspectos da produção e da comercialização (preços) desse PFNM na região de estudo. Com essas informações, obteve-se, conforme Mendes (1998), a margem e o "markup" de comercialização desse produto. Com o crescente conhecimento e utilização do chá-de-bugre, sua relevância econômica atual e seu potencial de mercado, houve a necessidade da implantação de medidas de regulamentação para promover ordenamento do processo e se compreender melhor o entendimento da cadeia produtiva. Como produto comercial, isso implica políticas de manutenção do extrativismo - exigindo a conservação da floresta, a criação de um cultivar para que possibilite a padronização de suas folhas na colheita e que haja mais qualidade no produto final - e a necessidade de adoção de novos modelos de regulação entre os diversos elos da cadeia produtiva, assim como melhora no nível de gestão e de conhecimento sobre plantio e comércio.

Palavra-chave: Cadeia produtiva; planta medicinal; comercialização de produtos florestais nãomadeireiros.
\end{abstract}

\begin{abstract}
"Cha-de-bugre" (Casearia silvestrys) productive chain in the Curitiba Metropolitan Region - Parana state. This article address the production and commercialization of Non Wood Forest Products (NWFP), in activity in the following cities: Curitiba, Campo Largo, Araucaria and Sao Jose dos Pinhais, between the months of August and December 2005. Its aim objective was to analyze "cha-de-bugre" (Casearia sylvestris) productive chain on Curitiba metropolitan region in Paraná State, as a medicinal plant. The method used in this analysis was based in interviews close to the producers, when were obtained information about production and commercialization of this NWFP on the study area. With this information it was possible calculate the margin and markup of commercialization of this product, based in Mendes (1998). With the increasing knowledge, and "cha-de-bugre" uses, its actual economic importance, and its potential market, generated a necessity to implement regulation procedures in order to promote the organization of the process, and a better understanding of the productive chain. As a market product, it implies policies of the maintenance of the its extractivism process, demanding the forest conservation, the creation of a "cultivar" that will make possible to have a pattern of leaves for harvesting, and provide more quality to the end product, in the necessity of new regulation models among the various parts of the productive chain, as well as a development of the level of management and knowledge concerning plantation and market.

Keywords: Productive chain; medicinal plant; non wood forest products commercialization.
\end{abstract}

\section{INTRODUÇÃO}

Segundo Lorenzi (1998), a espécie Casearia sylvestris, popularmente conhecida como chá-debugre, pertence à família Flacourtiaceae, é nativa da América do Sul e, no Brasil, vegeta em abundância, sendo uma espécie muito comum desde a Bahia até Santa Catarina. Devido à sua ampla distribuição pelo 
país, recebe diversos nomes populares, entre os quais cabe aqui mencionar: casca-branca, cegonha-dogentio, cotó, cotó-cotó, folha-grossa-do-sertão, louro-cravo, craveiro-do-mato e louro.

Teske; Trentini (1996) acrescentam que, "como produto, o chá-de-bugre é bastante difundido na medicina popular, e, na maioria das vezes, suas folhas são utilizadas como cicatrizante, anti-séptica, antimicrobiana, hemostática e depurativa do sangue, sendo empregadas no tratamento de aftas, herpes simples, úlceras gástricas, feridas, picadas de insetos, entre outras". Já os estudos feitos por Scavone et al. (1979) concluíram que "as folhas fornecem um extrato com propriedades anestesiantes, podendo ser usada na cirurgia dentária para acalmar as dores e como cicatrizante, e em pasta dental como antitártaro e no tratamento de gengivite". Lorenzi (1992), por sua vez, afirma que "as cascas têm as mesmas propriedades medicinais das folhas, de onde os índios extraem uma resina de aparência idêntica à do âmbar, com a qual fabricam ornamentos para os lábios".

Portanto, sendo uma planta medicinal, o seu valor intrínseco está no seu efeito terapêutico. Segundo Martins et al. (2000), "plantas medicinais são aquelas que contêm um ou mais princípios ativos, conferindo-lhes atividades terapêuticas", ou "qualquer planta que possua, em um ou em vários de seus órgãos, substâncias usadas com finalidade terapêutica, ou que essas substâncias sejam ponto de partida para a síntese de produtos químicos e farmacêuticos".

Diante desse cenário, tem-se que, com o crescente conhecimento e utilização do chá-de-bugre, sua relevância econômica atual e seu potencial de mercado, é oportuna a implantação de medidas de regulamentação para promover o ordenamento do processo como um todo. Para tal, justifica-se a realização de estudos que gerem informações que permitam compreender melhor o entendimento da sua cadeia produtiva.

Nesse contexto, Haddad (1999) contribui argumentando que "cadeia produtiva representa os encadeamentos entre as diversas fases por onde passa um produto, desde os fornecedores de insumos até o destino final da produção, buscando a satisfação do consumidor". Para Castro et al. (1998), a cadeia produtiva "é o conjunto de componentes interativos, incluindo os sistemas produtivos, fornecedores de insumos e serviços, indústrias de processamento e transformação, agentes de distribuição e comercialização, além dos consumidores finais de produtos e subprodutos".

Considerando o exposto, o presente artigo tem por objetivo analisar as principais etapas da cadeia produtiva do chá-de-bugre na Região Metropolitana de Curitiba, Paraná, assim como verificar a agregação de valor ao longo da cadeia por meio do cálculo das margens e "markups" de comercialização. Nesta análise, parte-se do pressuposto de que as cadeias produtivas de produtos florestais não-madeireiros são geralmente muito modificadas, e nelas o produtor representa o elo que possui a menor participação nas receitas geradas pelas atividades que as compõem.

Vale salientar que, considerando a inexistência de trabalhos científicos sobre a cadeia produtiva e a comercialização do chá-de-bugre, conforme constatado numa revisão bibliográfica sobre esse tema, evidencia-se o pioneirismo desta pesquisa, o que justifica, uma vez mais, a sua realização.

\section{MATERIAL E MÉTODO}

O material usado nesta pesquisa foi coletado em duas fases. Na primeira, os dados foram obtidos numa revisão bibliográfica realizada em revistas, periódicos e livros especializados em plantas medicinais. Na segunda fase, o material foi gerado numa pesquisa de campo realizada nos pontos de varejo, na cidade de Curitiba, Paraná, assim como foram entrevistados intermediários e produtores atuantes nas cidades de Campo Largo e Araucária, no Paraná, entre os meses de agosto e dezembro de 2005. Foram entrevistados três produtores no município de Campo Largo e dois em Araucária. Esse número de produtores correspondeu à população, uma vez que não havia, na data da pesquisa, outros produtores atuando nessa atividade na região. Também foram entrevistados três intermediários e três varejistas nos municípios já mencionados. Não há registros oficiais sobre o número de estabelecimentos que comercializam o chá-de-bugre.

A metodologia utilizada na pesquisa de campo constou da elaboração de um formulário com perguntas visando à descrição do processo de comercialização do chá-de-bugre, assim como a identificação dos principais componentes da cadeia produtiva, quantificando o fluxo físico e financeiro, adaptado de Castro; Lima; Hoeflich (2002). 
Para a quantificação da agregação de valor ao longo da cadeia, utilizou-se como ferramenta a margem e "markup" de comercialização, conforme (Mendes, 1998).

É oportuno mencionar que, durante a revisão bibliográfica, constatou-se que existem duas formas de se obter o chá-de-bugre. Mais especificamente, podem-se obter as plantas num processo extrativista ou como matéria-prima originária de plantas cultivadas. Assim sendo, na presente pesquisa, somente produtores que realizam o cultivo foram entrevistados, não sendo focada a atividade extrativa. Apesar desse fato, é descrito, de forma sucinta, a possibilidade da extração como etapa da cadeia produtiva.

A tabela 1 apresenta a fórmula da Margem Bruta de comercialização, que é mensurada pela diferença de preços entre os diferentes agentes que participam do processo de comercialização.

Tabela 1. Fórmulas para o cálculo da margem de comercialização.

Table 1. Commercialization margin formulas.

\begin{tabular}{lcc}
\hline Margem & Valor absoluto & Valor relativo \\
\hline Total $(\mathrm{Mt})$ & $\mathrm{Pv}-\mathrm{Pp}$ & {$[(\mathrm{Pv}-\mathrm{Pp}) / \mathrm{Pv}] 100$} \\
Intermediário & $\mathrm{Pi}-\mathrm{Pp}$ & {$[(\mathrm{Pi}-\mathrm{Pp}) / \mathrm{Pv}] 100$} \\
Atacado (Ma) & $\mathrm{Pa}-\mathrm{Pp}$ & {$[(\mathrm{Pa}-\mathrm{Pi}) / \mathrm{Pv}] 100$} \\
Varejo $(\mathrm{Mv})$ & $\mathrm{Pv}-\mathrm{Pa}$ & {$[(\mathrm{Pv}-\mathrm{Pa}) / \mathrm{Pv}] 100$} \\
\hline
\end{tabular}

Fonte: Mendes, 1998.

Pp: preço no nível do produtor, ou seja, preço de venda ao intermediário; Pi: preço no nível do intermediário, ou seja, preço de venda ao atacado; Pa: preço no nível do atacadista, ou seja, preço de venda ao varejo; Pv; preço no nível do varejo, ou seja, preço pago pelo consumidor.

Complementando, a tabela 2 mostra as fórmulas empregadas no cálculo do markup de comercialização.

Tabela 2. Fórmulas para o cálculo do markup de comercialização.

Table 2. Commercialization markup formulas.

\begin{tabular}{lcc}
\hline Margem & Valor absoluto & Valor relativo \\
\hline Total $(\mathrm{Mt})$ & $\mathrm{Pv}-\mathrm{Pp}$ & {$[(\mathrm{Pv}-\mathrm{Pp}) / \mathrm{Pp}] 100$} \\
Intermediário & $\mathrm{Pi}-\mathrm{Pp}$ & {$[(\mathrm{Pi}-\mathrm{Pp}) / \mathrm{Pp}] 100$} \\
Atacado $(\mathrm{Ma})$ & $\mathrm{Pa}-\mathrm{Pi}$ & {$[(\mathrm{Pa}-\mathrm{Pi}) / \mathrm{Pi}] 100$} \\
Varejo $(\mathrm{Mv})$ & $\mathrm{Pv}-\mathrm{Pa}$ & {$[(\mathrm{Pv}-\mathrm{Pa}) / \mathrm{Pa}] 100$} \\
\hline
\end{tabular}

Fonte: Mendes, 1998.

Pp: preço no nível do produtor, ou seja, preço de venda ao intermediário; Pi: preço no nível do intermediário, ou seja, preço de venda ao atacado; Pa: preço no nível do atacadista, ou seja, preço de venda ao varejo; Pv; preço no nível do varejo, ou seja, preço pago pelo consumidor.

\section{RESULTADOS E DISCUSSÃO}

Os dados coletados neste estudo permitiram a geração de informações sobre a cadeia produtiva do chá-de-bugre apresentadas a seguir.

\section{Caracterização da cadeia produtiva}

Conforme já mencionado, o processo de obtenção do chá-de-bugre pode se dar de duas formas: extrativa ou por meio de cultivos. A atividade extrativista tem origem na floresta ou em árvores existentes nos pastos. Assim, o primeiro elo da cadeia começa com o proprietário da floresta ou das árvores nas pastagens, que na maioria das vezes não tem nenhum interesse na exploração econômica do chá-de-bugre e cede ao coletor o direito da exploração com um único objetivo: fazer a limpeza do local. O cultivo inicia-se com o beneficiamento e acondicionamento das sementes, o preparo em viveiros, o transplante das mudas da sementeira para os recipientes e destes para o local definitivo, até o início da colheita.

A tabela 3 sintetiza as diversas etapas da cadeia produtiva do chá-de-bugre.

Em termos de produtos, existem algumas formas como os produtos à base de chá-de-bugre são disponibilizados no mercado. Uma delas é na forma de cápsulas, possuindo tamanhos e pesos variáveis, porém o mais usual é a de $0,5 \mathrm{~g}$. A forma de tintura consiste na extração com álcool do princípio ativo por meio da maceração e percolação do pó da folha. A forma rasurada é a comumente encontrada em lojas de plantas medicinais e aromáticas (chás), na forma de sachês. 
Tabela 3. Quantidades compradas e comercializadas, custos em reais, tipo de produto e valor de venda em reais por quilo ou litro nos diferentes elos da cadeia produtiva.

Table 3. Comercialized and bought quantities, costs $(\mathrm{R} \$)$, kind of product and retail price ( $\mathrm{R} \$ / \mathrm{kg}$ e $\mathrm{R} \$ / \mathrm{L}$ ) in the different stages of the productive chain.

\begin{tabular}{|c|c|c|c|c|c|}
\hline $\begin{array}{l}\text { Segmentos da cadeia } \\
\text { produtiva }\end{array}$ & $\begin{array}{l}\text { Quantidade } \\
\text { produzida }\end{array}$ & $\begin{array}{c}\text { Quantidade } \\
\text { comercializada }\end{array}$ & $\begin{array}{l}\text { Custos } \\
\text { (R\$) }\end{array}$ & $\begin{array}{l}\text { Tipo do } \\
\text { produto }\end{array}$ & $\begin{array}{c}\text { Preço } \\
\text { (R\$/kg/litro) }\end{array}$ \\
\hline Coletor & $\begin{array}{c}3000 \mathrm{~kg} \text { folhas verdes } \\
\text { semanais }\end{array}$ & $\begin{array}{c}500 \mathrm{~kg} \text { folhas } \\
\text { secas semanais }\end{array}$ & $0,15 / \mathrm{kg}$ & - & $0,55 / \mathrm{kg}$ \\
\hline Primeiro intermediário & $\begin{array}{c}500 \mathrm{~kg} \text { folhas secas } \\
\text { semanais }\end{array}$ & $\begin{array}{c}500 \mathrm{~kg} \text { folhas } \\
\text { secas semanais }\end{array}$ & $0,55 / \mathrm{kg}$ & $\begin{array}{c}\text { Folha picada e } \\
\text { seca }\end{array}$ & $1,10 / \mathrm{kg}$ \\
\hline Segundo intermediário & $\begin{array}{c}500 \mathrm{~kg} \text { folhas secas } \\
\text { semanais }\end{array}$ & $\begin{array}{c}500 \mathrm{~kg} \text { folhas } \\
\text { secas semanais }\end{array}$ & $1,10 / \mathrm{kg}$ & $\begin{array}{c}\text { Folha picada, seca } \\
\text { e moída }\end{array}$ & $1,70 / \mathrm{kg}$ \\
\hline $\begin{array}{l}\text { Indústria (laboratório) e } \\
\text { atacadista }\end{array}$ & $2.000 \mathrm{~kg}$ de estoque & Variável & $1,80 / \mathrm{kg}$ & $\begin{array}{l}1 \text { Rasurado } \\
2 \text { Pó } \\
3 \text { Extrato } \\
4 \text { Tintura } \\
\end{array}$ & $\begin{array}{c}5,00 / \mathrm{kg} \\
6,00 / \mathrm{kg} \\
35,00 / \mathrm{kg} \\
35,00 / \mathrm{kg} \text { ou } 1 \\
\end{array}$ \\
\hline Varejo & $\begin{array}{c}\text { Estoque para } \\
6 \text { meses }\end{array}$ & Variável & $\begin{array}{c}5,00 / \mathrm{kg} \\
6,00 / \mathrm{kg} \\
35,00 / \mathrm{kg} \\
35,00 / 1\end{array}$ & $\begin{array}{c}1 \text { Cápsula* } \\
2 \text { Tintura** } \\
3 \text { Rasurado*** }\end{array}$ & $\begin{array}{c}0,30(0,5 \mathrm{~g})^{*} \\
35,00(30 \mathrm{ml}) \\
1,70(30 \mathrm{~g}) \mathrm{ou} \\
56,00 / \mathrm{kg}\end{array}$ \\
\hline
\end{tabular}

Fonte: Pesquisa de campo, 2005.

\section{Coletores/produtores}

Os coletores, quando a exploração é extrativista, em sua maioria são compostos por pessoas que saem à procura de propriedades onde existam árvores de chá-de-bugre, e com a permissão do proprietário colhem as folhas e galhos. Quando o proprietário é quem explora, ele utiliza seus funcionários, que fazem o papel do coletor. Nesse caso, a atividade principal é outra, muitas vezes agricultura de subsistência e vaca de leite, mas utiliza a colheita da árvore de chá-de-bugre para melhorar sua renda.

$\mathrm{Na}$ situação dos cultivos, as mudas são plantadas nos locais definitivos e esses são reservados somente ao plantio das árvores de chá-de-bugre. O processo de colheita consiste em coletar e realizar a limpeza dos galhos e folhas. Após essa etapa, é realizada a secagem e, esporadicamente, costuma-se embalar o produto em sacas com oito quilos de folhas secas. Vale aqui mencionar que, em média, os grupos coletores, com até quatro pessoas, colhem 3.000 quilos de folhas verdes por semana, que depois de secas pesam 500 quilos. As vendas, por sua vez, são feitas ao primeiro intermediário por R 0,55 o quilo de folha seca, mas via de regra isso não ocorre, uma vez que, às vezes, o produtor vende diretamente ao laboratório e ao comércio varejista. A mão-de-obra para a colheita é remunerada à base de $\mathrm{R} \$ 0,15$ por quilo seco.

\section{Primeiro intermediário}

Essa etapa de comercialização é realizada por pessoas que, normalmente, residem próximo das bases de produção e vendem ao segundo intermediário por R $\$ 1,10$ o quilo de folha seca. Esse primeiro intermediário emprega alguns métodos de processamento para melhoria qualitativa desse produto, tais como a triagem, a picagem, a secagem e a embalagem.

A triagem consiste em uma simples separação de ramos e galhos das folhas, visando obter um material "limpo", pois a presença de tais resíduos interfere na aparência, no odor, no sabor, na cor, etc. do produto, dificultando a venda. A picagem, por seu turno, é utilizada para reduzir a dimensão das folhas, facilitando e maximizando a secagem do material. Saliente-se que o processo da secagem é necessário para a obtenção de um produto de qualidade inquestionável, proporcionando uma proteção extra contra os ataques de fungos e pragas. Por fim, a embalagem para a comercialização, a qual é realizada a granel, em sacos de $8 \mathrm{~kg}$.

\section{Segundo intermediário}

Constatou-se, no levantamento de dados para este estudo, que os integrantes da cadeia produtiva ora analisada denominados como segundos intermediários residem nas grandes cidades, principalmente em Curitiba e São Paulo, e entre seus fornecedores estão o produtor, o coletor e o primeiro intermediário. 
Esse segundo intermediário vende o produto aos laboratórios (indústrias) localizados nos estados de São Paulo e Paraná, por R\$ 1,70 o quilo da folha seca. Possui custos com o transporte, que é de difícil valoração, pois não trabalha apenas com chá-de-bugre, transportando outros produtos com o mesmo frete. Não é comum empregar algum tipo de beneficiamento, mas eventualmente o segundo intermediário faz a moagem das folhas picadas e secas e as embala em saquinhos com 30 gramas, vendendo-os diretamente às farmácias de manipulação de produtos fitoterápicos e homeopáticos e casas de produtos naturais. Já os que são comercializados diretamente em feiras são apenas acondicionados em embalagens apropriadas.

\section{Industrialização (laboratório) e comércio atacadista}

A etapa de industrialização (laboratório) funde-se à de comércio, pois assume característica de mercado atacadista e não trabalha apenas com o chá-de-bugre, dificultando, dessa forma, a quantificação de dados econômicos. No Paraná existem aproximadamente 15 fornecedores para 6 (seis) laboratórios, somente em Curitiba. O produto final repassado ao mercado varejista apresenta-se nas seguintes formas: pó, extrato seco, rasurado e tintura, porém o comércio mais comum nessa etapa é na forma rasurado.

No Laboratório, o produto passa pelos seguintes processos:

a) Controle de Qualidade: é a etapa inicial, realizada no produto a ser adquirido junto aos fornecedores, na qual são aplicados testes específicos, tais como análise da matéria-prima, identificando a botânica (macroscópica/microscópica), testes físico-químicos e de doseamento do princípio ativo.

b) Moagem: é a redução do produto na forma de folhas a pó, realizado nos casos em que o intermediário ainda não o fez.

c) Esterilização: são contratados serviços terceirizados para a realização dos testes, caso o intermediário não o tenha realizado.

d) Encapsulamento e demais embalagens.

e) Tintura: é a extração do princípio ativo da planta através do processo de maceração e percolação, utilizando como veículo extrator água e/ou álcool. Após a extração, a tintura é analisada e, quando aprovada pelo controle de qualidade, segue para o equipamento que fará o envasamento. Depois, os produtos acabados são analisados por amostragem de lotes e, se aprovados, já estão prontos para serem colocados à venda.

f) Cápsulas: é a transformação das folhas, galhos, cascas e raízes em cápsulas medicinais.

Não foi possível dimensionar a capacidade instalada da indústria, pois os procedimentos industriais não são fundamentados exclusivamente para o chá-de-bugre. Por exemplo, a encapsuladeira é utilizada para várias espécies de plantas medicinais. É mantido um estoque regulador de cerca de 2.000 quilos de produto seco nos laboratórios. A compra é baseada nos índices de baixa ou alta do estoque.

Os custos oriundos do processo industrial são de difícil obtenção, pois os laboratórios não trabalham única e exclusivamente com o chá-de-bugre. Recursos produtivos, tais como trabalhos, capital fixos, circulantes, humanos e financeiros, são utilizados em todo mix de produto, o que dificulta o cálculo individual dos custos. Não costumam considerar a depreciação e a mão-de-obra própria como custos. $\mathrm{O}$ transporte é realizado conforme o acerto feito entre o fornecedor e o laboratório. Não há uma regra, mas em geral o custo é do fornecedor. O laboratório adquire o produto do segundo intermediário por R $\$ 1,70$ o quilo seco, mas é comum nesse negócio o produtor (coletor) vender diretamente ao laboratório. Este possui clientela composta por estabelecimentos diversos. Vendem para o varejo por R $\$ 5,00$ o quilo rasurado, R\$ 6,00 em pó, R\$ 35,00 em extrato seco e um litro de tintura.

\section{Comércio varejista}

O mercado varejista é composto, principalmente, por farmácias de manipulação de produtos fitoterápicos e homeopáticos e casas de produtos naturais, podendo contar, também, com vendas em farmácias comuns e feiras-livres. No caso das farmácias de manipulação e casas de produtos naturais, o produto recebe processamento detalhado e específico, sendo exposto à venda através de uma gama ampla de formas. Nas feiras, o produto encontra-se bruto ou com processamento mínimo.

Já nas farmácias de manipulação e nas casas de produtos naturais, obtém-se o produto diretamente de laboratórios atacadistas, onde o chá-de-bugre é devidamente processado, e são feitos testes visando confirmar a qualidade, através de análises fitoquímicas, entre as quais, para verificação de solubilidade, aspecto, propriedades organolépticas e densidade, entre outras. No que se refere às feiras, estas adquirem diretamente do produtor (coletor) ou dos intermediários e não costumam fazer testes de qualidade. Quanto ao mercado externo, não há dados de exportação. Contudo, há o comércio interestadual 
do produto, principalmente para os estados das regiões Sudeste e Sul. O preço final, exposto ao consumidor, varia conforme a forma como é vendido:

a) Em embalagem (pacote) de $30 \mathrm{~g}$ do produto rasurado (seco), custa $\mathrm{R} \$ 1,70$, ou $\mathrm{R} \$ 56,00 \mathrm{o} \mathrm{kg}$.

b) Em unidade da cápsula (a mais usual é a de $500 \mathrm{mg}$ ), são vendidas a $\mathrm{R} \$ 0,30$. As cápsulas possuem pesos variáveis (180 mg, $330 \mathrm{mg}, 500 \mathrm{mg}, 750 \mathrm{mg}$ e 1,5 g).

c) Em tintura são vendidas a R $\$ 35,00$ cada $30 \mathrm{ml}$.

As compras no varejo são realizadas em função de variação de estoques. Por exemplo, compramse $50 \mathrm{~kg}$ da forma rasurada e um litro na forma de tintura, com previsão de venda total em um semestre, nas farmácias especializadas e nas casas de produtos naturais.

\section{Margem de comercialização na cadeia produtiva do chá-de-bugre}

Com base nas informações de preço nos diferentes níveis da cadeia produtiva, foi possível obter a margem de comercialização. A tabela 4 apresenta os preços de venda e a margem de comercialização em percentual nos diferentes agentes da cadeia produtiva do chá-de-bugre.

Tabela 4. Preço de venda e margem de comercialização entre os diferentes agentes da cadeia produtiva do chá-de-bugre.

Table 4. Retail price and commercialization margin between the different stages of chá-de-bugre productive chain.

\begin{tabular}{|c|c|c|c|c|c|c|}
\hline \multirow[b]{2}{*}{ Item } & \multicolumn{5}{|c|}{ Preços de venda em reais e margem de comercialização (\%) } & \multirow{2}{*}{$\begin{array}{c}\text { Margem } \\
\text { total } \\
(\%)\end{array}$} \\
\hline & Coletor & $\begin{array}{c}\text { Primeiro } \\
\text { Intermediário }\end{array}$ & $\begin{array}{c}\text { Segundo } \\
\text { Intermediário }\end{array}$ & $\begin{array}{c}\text { Indústria } \\
\text { (Laboratório) }\end{array}$ & Varejo & \\
\hline $\begin{array}{l}\text { Preço de venda } \\
(\mathrm{R} \$ / \mathrm{kg})\end{array}$ & 0,55 & 1,10 & 1,70 & $5,00^{*}$ & $56,00^{*}$ & - \\
\hline Margem (em \%) & - & 1,00 & 1,10 & 5,90 & 91,10 & 99,00 \\
\hline
\end{tabular}

Os dados dessa tabela evidenciam os diferentes preços a partir da indústria do produto na forma rasurado, e evidenciam que para os diferentes tipos das etapas de produção, há um aumento nos percentuais de margem de comercialização, a partir do produtor até o consumidor final.

O varejo é o agente que se apropria da maior fatia dos ganhos em relação ao preço pago pela indústria $(91,1 \%)$. O mesmo se repete com a indústria (laboratório) em relação ao $2^{\circ}$ intermediário, com $5,9 \%$. A menor margem de comercialização é a do $1^{\circ}$ intermediário em relação ao coletor (1\%), seguido do $2^{\circ}$ intermediário em relação ao primeiro $(1,1 \%)$. Entre o varejo e o coletor, a margem de comercialização é de 99,0\%. Essa diferença é crescente a partir da indústria (laboratório), devido ao produto passar por diversos processos de agregação de valor, conforme mencionado anteriormente.

"Markup" de comercialização na cadeia produtiva do chá-de-bugre

Têm-se, na tabela 5, os valores de preço e de markup de comercialização entre os agentes da cadeia produtiva do chá-de-bugre.

Tabela 5. Preço de venda e markup de comercialização entre os diferentes agentes da cadeia produtiva do chá-de-bugre.

Table 5. Retail price and commercialization margin between the different stages of cha-de-bugre productive chain.

\begin{tabular}{|c|c|c|c|c|c|c|}
\hline \multirow[b]{2}{*}{ Item } & \multicolumn{5}{|c|}{ Preços de venda em reais e markup de comercialização (\%) } & \multirow{2}{*}{$\begin{array}{c}\text { Markup total } \\
(\%)\end{array}$} \\
\hline & Coletor & $\begin{array}{c}\text { Primeiro } \\
\text { intermediário }\end{array}$ & $\begin{array}{c}\text { Segundo } \\
\text { intermediário }\end{array}$ & $\begin{array}{c}\text { Indústria } \\
\text { (laboratório) }\end{array}$ & Varejo & \\
\hline Preço de venda $(\mathrm{R} \$ / \mathrm{kg})$ & 0,55 & 1,10 & 1,70 & $5,00^{*}$ & $56,00 *$ & - \\
\hline Markup em \% & - & 100,00 & 55,00 & 194,00 & $1.020,00$ & $10.082,00$ \\
\hline
\end{tabular}

Fonte: Pesquisa de campo, 2005.

*: Valor de venda na forma rasurada.

O chá-de-bugre é vendido ao $1^{\circ}$ intermediário pelo coletor por $\mathrm{R} \$ 0,55$ o quilo de folhas secas. 
Esse intermediário revende esse mesmo produto ao $2^{\circ}$ intermediário por $\mathrm{R} \$ 1,10$ o quilo, obtendo um markup de comercialização de $100 \%$. O $2^{\circ}$ intermediário, por sua vez, revende esse mesmo produto para a indústria (laboratório) por R\$ 1,70 o quilo, obtendo um markup de 55\%. A indústria, depois de fazer vários processamentos, vende o produto na forma rasurado a $\mathrm{R} \$ 5,00$ (cinco reais) o quilo, obtendo um markup de 194\%.

Finalizando a cadeia de comercialização, o comércio varejista comercializa o produto para o consumidor por R\$ 56,00 o quilo, obtendo um markup de $1.020 \%$. É o agente da cadeia que obtém os maiores markups de comercialização. Essa diferença, nessa etapa, é ampliada devido ao fato de que, nesse tipo de comércio, o consumidor compra o produto em parcelas que iniciam em 30 gramas. Não é comum vender um quilo para um único consumidor. O markup total de comercialização entre o coletor e o consumidor final atinge $10.082 \%$, ou seja, o consumidor final chega a pagar $10.082 \%$ a mais do que o preço pago ao produtor.

Esses números evidenciam o que na realidade vem ocorrendo na região de estudo, ou seja, uma redução no número de pessoas envolvidas na atividade de produção de chá-de-bugre, fato esse verificado quando das entrevistas em que os produtores afirmaram outrora haver outros produtores na região, que desmotivados com a remuneração do seu trabalho, deixaram a atividade.

\section{CONCLUSÕES}

A cadeia produtiva tem como característica principal em sua composição a ocorrência de pequeno número de agentes, como decorrência da inexistência de processos mais complexos de beneficiamento em seu início, porém apresenta características distintas ao longo do processo, já que, a partir da indústria (laboratório), o chá-de-bugre passa por diversos processos que exigem tecnologias e equipamentos indispensáveis para a execução dos serviços, gerando variedade de produtos, importante no atendimento das necessidades do consumidor.

No mercado varejista, o produto é vendido na forma rasurada, "a mais utilizada", em cápsula ou tinturas. As embalagens variam desde 30 gramas, porém as mais usuais são as de 500 gramas. Nessa etapa, quando comercializado por farmácias e casas de produtos naturais, o chá-de-bugre passou por todos os testes de qualidade, através de análise fotoquímica, porém nas feiras isso não ocorre.

$\mathrm{Na}$ margem de comercialização e no markup, os maiores lucros são apropriados pelo varejo. A margem total de comercialização é de $99 \%$, enquanto o markup é de $10.082 \%$. E na etapa final que o produto se modifica, devido à agregação de valor, ocorrido na indústria (laboratório), e na forma de comercialização pelo varejo.

Recomenda-se que o setor crie formas de melhorar a harmonia entre os elos da cadeia produtiva, para que todos possam se aperfeiçoar mais na atividade, desenvolver metodologias mais eficazes em resultados, concentrando esforços no aperfeiçoamento dos procedimentos mercadológicos, de preços, de atendimento, de qualidade e de melhoria tecnológica, para garantir ao consumidor maior segurança no consumo e assim poder atender a demanda com preço justo.

Isso implica também políticas de incentivo aos plantios comerciais em detrimento ao extrativismo sustentável, buscando incentivar ações que visem à integração de pesquisas, pois, na medida em que aumenta a demanda, torna-se impossível o atendimento somente com a produção extrativista sustentada. Porém, como grande parte da produção vem de espécie selvagem, é necessária a criação de um cultivar para que se possibilite a padronização de suas folhas na colheita e haja mais qualidade no produto final, o que resultará na necessidade de novos modelos de regulação entre os diversos elos da cadeia produtiva, assim como melhora no nível de gestão e de conhecimento sobre plantio e comércio, pois esse mercado sinaliza para uma crescente importância em tecnologia, como fator de competitividade, e de sucesso nos negócios, e os atores envolvidos precisam interagir e harmonizar o trabalho em todos os segmentos.

\section{REFERÊNCIAS}

CASTRO, A. M. G.; LIMA, S. M. V.; HOEFLICH, V. A. Cadeias Produtivas: Curso de capacitação de equipes para a realização de estudos prospectivos de cadeias produtivas agro-industriais. TECPAR. Curitiba. 2002.

CAStro, A. M. G.; LiMA, S. M. V.; FreitAS, A. F.; VASCONCELOS, J. R. F. (Eds.) Cadeias produtivas e sistemas naturais: prospecção tecnológica. Brasília, DF: Embrapa-DPD, 1998. 
HADDAD, P. R. (org). A competitividade do agronegócio e desenvolvimento regional: estudo de “cluster". Brasília: CNPQ/EMBRAPA, 1999.

MARTINS, E. R.; CASTRO, D. M.; CASTEllani, D. C.; DIAS, J. E. Plantas medicinais. Viçosa, MG: UFV, 2000. 220 p.

LORENZI, H. Árvores brasileiras: manual de identificação e cultivo de plantas arbóreas nativas do Brasil. Nova Odessa: Plantarum, 1992. p. 115.

LORENZI, H. Árvores brasileiras: manual de identificação e cultivo de plantas arbóreas nativas do Brasil. 2. ed. Nova Odessa: Plantarum, 1998.

MENDES, J. T. G. Economia Agrícola: princípios básicos e aplicações. Curitiba: ZNT, 1998.

SCAVONE, O.; GRECCHI, R.; PANIZZA, S.; SOUZA, E.; SILVA, R. A. P. Guaçatonga (Cesearia sylvestris Swartz): aspectos botânicos da planta, ensaios fotoquímicos e propriedades cicratizantes da folha. Anais de Farmácia e Química, São Paulo, v. 19, n. 1, p. 73-81, 1979.

TESKE, M.; TRENTINI, A. M. M. Herbarium: compêndio de fototerapia, 2. ed. Curitiba: Herbarium Laboratório Botânico, 1996. p. 158-159. 